\title{
A DIVINA COMÉDIA: DA ESCRITA DE DANTE À PERFORMANCE DE BENIGNI
}

\author{
Commedia: from Dante's writing to Benigni's performance
}

\author{
Fernanda Moro Cechinel \\ https://orcid.org/0000-0002-0697-2869 (0) \\ Universidade Federal de Santa Catarina, Programa de Pós-Graduação em Literatura \\ Florianópolis, SC, Brasil. 88040-900 - ppglitufsc@gmail.com
}

Resumo: Partindo dos pressupostos teóricos de que a performance é um ato de transferência (TAYLOR, 2013) e de que a poesia se realiza quando vocalizada (ZUMTHOR, 2007), pode-se chegar ao projeto Tutto Dante, de Roberto Benigni. Inspirado na obra Divina Comédia, de Dante Alighieri, o projeto, que percorreu a Europa e o continente americano no início do século XXI, teve por objetivo levar ao conhecimento do público uma das grandes obras da literatura ocidental e, também, reconhecida como mãe da língua italiana. A obra dantesca, desde sua publicação, ainda no século XIV, despertou o desejo de leitores para que ganhasse voz, segundo teoriza Paul Zumthor (2007). O primeiro que se tem conhecimento a fazer isso foi Giovanni Boccaccio, o mesmo que acrescentou o adjetivo Divina à obra. O presente trabalho tem por objetivo fazer uma breve análise do projeto Tutto Dante, partindo dos pressupostos teóricos da performance, escrita e vocalização, como trazem, principalmente, Aleida Assmann (2011), Arturo Carrera (2014), Diana Taylor (2013) e Paul Zumthor (2007).

Palavras-chave: Divina Comédia. Performance. Poesia. Escrita. Voz.

\begin{abstract}
Taking into consideration the theoretical background that performance is an act of transference (TAYLOR, 2013) and that poetry happens when vocalized (ZUMTHOR, 2007), the project Tutto Dante, by Roberto Benigni, comes to mind. The project, inspired in Dante Alighieri's Commedia, active in Europe and the American Continent in the beginning of the $21^{\text {st }}$ century, had as a purpose make public the work considered as founder of the modern occidental literature and preceding of the Italian language. Since its publication, in the $14^{\text {th }}$ century, readers of the Dantesc work have wished that it gained voice, as theorized by Paul Zumthor (2007). The first person known to do that was Giovanni Boccaccio, the same who added the adjective Divine to the work. The objective of the present work is to make a brief analysis of the project Tutto Dante, bearing in mind the theoretical background of performance, writing and vocalization, as discussed by Aleida Asmann (2011), Arturo Carrera (2014), Diana Taylor (2013), and Paul Zumthor (2007).
\end{abstract}

Keywords: Commedia. Performance. Poetry. Writing. Voice.

\section{Introdução}

La poesia alta non è solo nella penna, nella mano e nella testa di chi scrive, ma è soprattutto nell'orecchio di chi ascolta. (BENIGNI, 2012)

No século XIV, o poeta e filósofo Dante Alighieri oferecia ao mundo aquela que ficaria conhecida como uma das grandes obras da literatura ocidental, a Commedia. Tempos depois, Giovanni Boccaccio qualificaria a obra como Divina e, a partir de 1555, na edição 
veneziana de Ludovico Dolce, a obra dantesca passaria a se chamar Divina Comédia (PICCAROLO, 1946), título que permanece até hoje. Mas como é que uma obra permaneceu viva após sete séculos de sua escrita? Indiscutivelmente, boa parte desse mérito se deve à escrita de Dante, mas também ao trabalho dos editores, prefaciadores e críticos responsáveis pelas edições da obra, bem como às produções artísticas que se baseiam na Divina Comédia. Dentre essas, destacam-se as performances que, além de contribuírem para à propagação e permanência da obra entre os clássicos da literatura mundial, deram voz à poesia (ZUMTHOR, 2007) de Dante. Um exemplo disso é o projeto Tutto Dante, do também italiano Roberto Benigni, conhecido ator que ganhou notoriedade mundial com o filme $A$ vida é bela (1997), no qual dirigiu e atuou na trama sobre o holocausto, em partes, inspirada na vida de seu pai. Além de ator e diretor, Benigni, que nasceu no início dos anos 1950 na Toscana (Itália), também é comediante e, como se verá neste trabalho, performer da Divina Comédia.

Dante escreveu a Divina Comédia durante seu período de exílio, provavelmente nas primeiras décadas do século XIV. Quando o escritor italiano morreu, sua obra ainda se resumia a manuscritos, que assim circulavam. Após sua morte, o material foi reunido e passou a ser difundido dessa forma. Com a obra publicada, o público leitor se deparou com uma nova língua, que não era o latim de De Vulgari Eloquentia (1305 c.), mas sim um apanhado de línguas, que resultou no que hoje se conhece como língua italiana (PICCAROLO, 1946).

O enredo do poema dantesco consiste na viagem de Dante (personagem) pelo mundo dos mortos; lá chegando, Dante depara-se com o poeta Virgílio, que o guia pelo Inferno e Purgatório; já no Paraíso, Dante tem como guias Beatriz, aquela que o inspirava, e São Bernardo. Diante desse esplendor de forma e conteúdo, alguns leitores da obra dantesca resolveram performatizá-la, com o intuito de que o texto de Dante pudesse chegar a mais leitores, garantindo com isso, além da sua publicidade, sua sobrevivência. Boccaccio, provavelmente, foi o que se pode chamar de primeiro performer da Divina Comédia dantesca, ao ser contratado pela administração da cidade de Florença para ler publicamente a obra:

A primeira das Esposizioni sopra la Comedia di Dante (título com que seriam
publicadas as aulas de Boccaccio) foi ministrada no dia 23 de outubro de
1373 , na deteriorada igreja beneditina de Santo Stefano in Badia. A
audiência era formada sobretudo por gente do povo, mas certamente alguns
literatos também frequentaram as aulas. No contrato, previa-se que os
comentários deveriam se desenrolar durante todo o ano, dia após dia, com
exceção dos feriados e fins de semana; no entanto, depois de
aproximadamente sessenta sessões, no início de 1374 , o professor caiu
doente e a atividade foi interrompida na leitura do canto XVII do Inferno
(STERZI, 2008, p. 17-18, grifo do autor).

Na ocasião, a leitura pública da Divina Comédia causou desconforto, os teólogos chamaram a obra de herética, já os humanistas viram na leitura uma forma de vulgarizar o poema. Vulgar ou herética, o fato é que Boccaccio iniciou uma tradição que até hoje perdura 
e recebe o nome de lecturae dantis (STERZI, 2008).

Já no século XX, outro notável propagador da Divina Comédia foi Vittorio Sermonti que, entre os anos de 1987 e 1992, via rádio, fez a obra de Dante ser ouvida por um grande público na Itália. No século XXI, tem-se Roberto Benigni com o projeto Tutto Dante, que consistiu nas leituras dramatizadas de alguns cantos da Divina Comédia. As primeiras performances ocorreram em 2006, na Grécia, no Teatro Patrasso, e, em Florença, na Piazza Santa Croce, lugares simbólicos para as artes, pois uma é o berço do teatro e a outra é a terra onde nasceu Dante.

No entanto, antes de falarmos sobre as apresentações aqui citadas, se faz necessário compreender a teoria sobre a qual este artigo se embasa. Para tanto, será feito um apanhado sobre o que estudiosos como Diana Taylor (2013) e Paul Zumthor (2007) refletiram sobre o tema performance.

\section{A performance e alguns teóricos}

De acordo com Taylor (2013), a performance tem sua gênese por volta dos anos de 1970, oriunda da antropologia e do teatro. Performances, segundo ela, são "atos de transferência”. E o que isso significa? Significa ver as performances como uma ação, que parte de um indivíduo em direção ao outro: do artista no palco ao público que o prestigia. Essa transferência, também está relacionada com a transmissão dos conhecimentos dentro de uma cultura.

No entanto, essa não é a única definição do termo que, assim como sua origem, possui divergências:

As performances funcionam como atos de transferência vitais, transmitindo o conhecimento, a memória e um sentido de identidade social por meio do que Richard Schechner denomina "comportamento reiterado". Em um primeiro nível, a performance constitui o objeto/processo de análise nos estudos da performance, isto é, as muitas práticas e eventos [...] que envolvem comportamentos teatrais, ensaiados ou convencionais/apropriados para a ocasião (TAYLOR, 2013, p. 27).

Logo, baseando-se em Taylor (2013), entende-se como performance as manifestações feitas repetidas vezes ("comportamento reiterado"), tendo o corpo como instrumento e, dentro de um contexto que objetiva transmitir algo. Esse pensamento de Taylor (2013) tem como um dos seus propulsores, um evento do Instituto Hemisférico de Performance e Política ocorrido em 2003, cujo objetivo era pensar as performances como um instrumento crítico "para intervir nos cenários políticos" (TAYLOR, 2013, p. 25).

No evento, no qual Taylor (2013) pautou suas reflexões, Tito Vasconcelos, performer mexicano da década de 1980, apareceu no palco fantasiado de Marta Sahagún, que, na época, era amante do então presidente do México (TAYLOR, 2013). Esse é apenas um exemplo de como a performance, além da sua característica artística, também pode ter um papel político. Outras formas, citadas por Taylor (2013) ao longo do texto, de inserções políticas da performance são as body arts, os escraches e os protestos em forma de peças 
teatrais.

Ao compreender a performance como veículo transmissor da memória, surge outro elemento, uma espécie de suporte a essa mesma memória, nesse caso, a escrita (ASSMANN, 2011). Utilizando a nomenclatura de Taylor (2013), que analisa a performance em dois níveis, esse seria o primeiro nível nos estudos performativos. Por mais que autora não aprofunde na explanação desses níveis, podemos depreender algumas informações úteis para o nosso trabalho.

No primeiro nível, a performance seria seu próprio objeto de análise, tendo um conceito ontológico, ligando-se ao ser e dele depender para acontecer. Aqui também, Taylor (2013) traz um viés cultural, no sentido de que, o que é performance em uma cultura pode não ser entendido como performance em outra.

Já "em um segundo nível, a performance também constitui a lente metodológica que permite que pesquisadores analisem eventos como performances" (TAYLOR, 2013, p. 27), ou seja, se primeiro tínhamos a performance como objeto de análise, aqui ela aparece como método para essa análise, o que Taylor (2013) chama de conceito epistémico. Esses eventos seriam algumas atividades, que acontecem com certa frequência publicamente e, são passíveis de serem estudados.

Ao longo do seu trabalho, Taylor (2013) buscou relacionar performance e memória. No presente estudo, compreender-se-á a memória segundo o entendimento de Aleida Assmann (2011), de ars (arte) e vis (potência). Ao ver a memória como arte, e, arte no sentido de técnica, surge a escrita como um dos aparatos que darão suporte a essa memória.

Neste ponto de nossa reflexão, é válido pensar que a literatura escrita, tal como a conhecemos hoje, teve sua gênese na oralidade. Milman Parry (1932), considerado um dos pioneiros nos estudos da tradição oral à tradição escrita, baseado em suas pesquisas na lugoslávia, buscou estabelecer um marco temporal para a transição da oralidade para a palavra escrita dos poemas homéricos, Ilíada e Odisseia, fato esse ocorrido por volta do século VIII a.C. (WEST, 2001). Gustavo Junqueira Duarte Oliveira (2008), reunindo outros pesquisadores dessa seara, como Albert Bates Lord (1960) e G.S. Kirk (1962; 1965), apresenta a presença da literatura escrita por volta de VI a.C. a II a.C., em Atenas. Então, a partir do século II a.C., já se registraria a existência de editores alexandrinos. Muitos desses trabalhos focam na possível perda de uma naturalidade poética, ao se sair da produção oral para a técnica da escrita. No entanto, o enfoque aqui, ao contextualizar o leitor nesse processo de transição é, acima de tudo, apresentar a escrita dos textos literários como mais um dispositivo ao armazenamento dessas histórias (ASSMANN, 2011), assim como também concebiam as culturas astecas, maias e incas, nas quais, "a escrita, apesar de altamente valorizada, era originalmente um lembrete para a performance, um auxílio mnemônico" (TAYLOR, 2013, p. 46).

Saindo da tradição estritamente oral para a escrita, tem-se a divulgação desse material que, primeiramente, passou a ser reproduzido através da ação dos copistas em 
manuscritos, e, séculos mais tarde, com a invenção da imprensa (século XV), esses registros escritos alcançariam uma maior amplitude.

Para Assmann (2011), a escrita funciona como um meio para a eternização do poeta e um suporte da memória:

[...] já os antigos egípcios enalteciam a escrita como o medium mais seguro da memória. Quando olhavam retrospectivamente para a própria cultura, em um lapso temporal de mais de mil anos, ficava-lhes claro que construções colossais e monumentos jaziam em ruínas, mas os textos daquela mesma época ainda eram copiados, lidos e estudados. Assim, constataram que vestígios de tinta preta sobre um papiro frágil perfaziam um monumento mais duradouro que túmulos caros com ornamentação dispendiosa. Um papiro do século XIII de nossa era compara a força preservadora de túmulos e livros e chega, com isso, ao resultado de que a escrita é uma das armas mais eficientes contra a segunda morte social, o esquecimento (ASSMANN, 2011, p. 195, grifo da autora).

Dante, ao escrever, no sentido literal, imprimiu sua letra que, aliada à sua genialidade fez com que sua obra adentrasse aos séculos. Hoje não se tem os manuscritos originais da Divina Comédia ou o áudio primeiro dos poemas de Homero, contudo, eles continuam presentes porque, em algum momento, foram escritos, transcritos, copiados, reproduzidos e, assim, são, no vai e vem dos séculos, resgatados, seja através de uma obra literária, seja através de uma performance.

Séculos depois, já que a poesia partiu da voz para a letra, eis que novamente se utiliza o recurso da oralidade para com as obras literárias. Um dos fatores pelos quais tal recurso foi utilizado, como no caso da Divina Comédia, foi para que um maior e vasto público tivesse acesso à obra. Se, como diz Zumthor (2007), os poetas são "compelidos a realizarem vocalmente sua poesia" (ZUMTHOR, 2007, p. 10), Dante despertou nos outros artistas esse desejo, como ocorreu no caso de Sermonti e Benigni, ao oralizarem a Divina Comédia.

O medievalista Zumthor, além de focar seus estudos na poesia oral, também adentrou na perspectiva da performance. Em sua obra A letra e a voz: a "literatura" medieval (1993), o intelectual suíço propôs um resgate da história. Segundo ele, na Idade Média, os artistas, como os trovadores, sem o auxílio da escrita, cantavam seus poemas. Pautado nos estudos de M. Clanchy sobre a Inglaterra dos séculos XII e XIII, Zumthor (1993) diz que ler e escrever eram aprendizados distintos. Assim como Martin Litschfield West (2001) e Oliveira (2008), que apontam estudos nos quais é relatada a divergência quanto ao entendimento de quem passou para a escrita os poemas de Homero, se ele mesmo ou uma outra pessoa, uma vez que não se pode afirmar que o autor de Ilíada e Odisseia conhecia suficientemente as letras a ponto de transcrever suas obras.

Mesmo com a invenção da imprensa, a propagação, em larga escala, das obras literárias escritas não se deu de imediato, pois, dentre outras dificuldades, a tiragem era pouca, os volumes não eram de fácil manuseio, a iluminação era precária e o público letrado era consideravelmente pequeno. Logo, por mais que houvesse o aparato escrito, a leitura dos textos ainda era feita oralmente. Situação essa que só mudaria nos idos do século XV, 
com as bibliotecas públicas das universidades, que impuseram o silêncio nesses ambientes (ZUMTHOR, 1993), favorecendo a leitura individual dos livros.

Verifica-se que produção oral e escrita se alternaram ao longo dos séculos, na balança da valorização. O que se sabe até agora é que Dante, apesar de ter escolhido outra língua que não fosse o latim, para a escrita de sua Divina Comédia, tinha como objetivo mostrar que outras línguas também poderiam produzir bons textos, bem como para que a leitura fosse acessível a um maior número de pessoas. Não são conhecidos estudos que abordem a intenção do autor de que sua obra fosse transmitida pelo formato oral. No entanto, desde Boccaccio até hoje, diversas são as manifestações orais da obra dantesca.

No posfácio de A letra e a voz de Paul Zumthor, escrito por Jerusa Pires Ferreira em colaboração com Amálio Pinheiro (1993), diz-se que, para Zumthor, "a oralidade se faz um princípio do texto poético, permitindo-lhe deslocar a dicotomia popular/erudito, evitando discriminações" (FERREIRA, 1993, p. 287). Como será visto na sequência desse trabalho, havia justamente essa preocupação em relação ao projeto de Benigni, o de, ao performatizar uma obra clássica, tirá-la do espaço do erudito e colocá-la no âmbito popular.

No posfácio, Ferreira acrescenta que, para Zumthor, a poesia é "tanto um conjunto de textos ditos poéticos como a atividade que os produziu: o corpo, o gesto, os meios" (FERREIRA, 1993, p. 293). Além da questão da oralidade, o medievalista também agrega outros elementos aos seus estudos, como o receptor do que está sendo performatizado e do corpo, presente tanto em quem faz como no público que assiste a performance. $E$, sobre esse tema, Zumthor (1993) teoriza "tecnicamente, a performance aparece como uma ação oral-auditiva complexa, pela qual uma mensagem poética é simultaneamente transmitida e percebida, aqui e agora" (ZUMTHOR, 1993, p. 227).

Em outra obra, Performance, recepção, leitura, Zumthor (2007) aprofunda seus conceitos relativos à performance, a qual define como: "[...] reconhecimento. A performance realiza, concretiza, faz passar algo que eu reconheço, da virtualidade à atualidade" (ZUMTHOR, 2007, p. 31) e acrescenta que ela "é o único modo vivo de comunicação poética" (ZUMTHOR, 2007, p. 34) vivo, aqui utilizado no sentido de eficaz.

Esse transferir ao outro (TAYLOR, 2013), somado ao modo vivaz de trazer a obra ao presente e lhe dar voz (ZUMTHOR, 2007), foi a proposta do projeto Tutto Dante: a performance de uma obra escrita há sete séculos ressignificada pelo corpo, voz e gestos do ator Roberto Benigni.

\section{Tutto Dante: a Commedia segundo Benigni}

O projeto Tutto Dante, protagonizado por Roberto Benigni entre os anos de 2006 a 2013, foi um espetáculo (nos termos de Guy Debord (apud TAYLOR, 2013, p. 41), "espetáculo não é uma imagem, mas uma série de relações sociais mediadas pelas imagens") que saiu das praças, adentrou teatros e virou programa de TV. O espaço da performance era composto por Benigni, um microfone, pedestal para apoio do texto e uma orquestra, que fazia o acompanhamento musical. Dividida em duas partes, Benigni, além 
de fazer a leitura de um dos cantos da obra dantesca, fazia também uma sátira sobre a política italiana no período: o governo questionável de Berlusconi ${ }^{1}$. Nesse ponto, podemos remeter à relação que Taylor (2013) estabelece entre performance e política. Além da intenção de Benigni de apresentar a Divina Comédia de uma outra forma que não a do texto escrito, ele utiliza sua apresentação como instrumento para manifestar sua opinião política.

A relação de Benigni com a Divina Comédia não é de hoje. Em inúmeros momentos, em suas entrevistas e participações em programas de TV, o comediante italiano declamou trechos da obra dantesca, chamando a atenção pela sua capacidade de memorizar os cantos, o que ele chama de "dantemente" (Dante + mente).

Em uma entrevista para o jornalista italiano Andrea Bellandi, do jornal online Toscana Oggi, em 2012, Benigni falou sobre o porquê do Tutto Dante: "Tenho um sonho: fazer toda a Divina Comédia, comentá-la e lê-la em público, como ainda não foi feito" (BENIGNI, 2012, n.p, tradução nossa) ${ }^{2}$. E, sobre as apresentações, em entrevista concedida à agência internacional de notícias Reuters (2009), Benigni disse: "Não sou professor - sou um showman [...] não esperem comentários ou notas de rodapé" (ITALIANO, 2009, n.p).

No entanto, tal como Boccaccio, Benigni também teve quem apoiasse a sua ideia, como Bellandi (2012), que comentou sobre as apresentações do projeto:

[...] eles tiveram o mérito de apresentar a obra prima dantesca além das aulas nas escolas ou dos círculos de intelectuais na qual permaneceu confinada por tanto tempo, fazendo o grande público ver a extraordinária atualidade e escopo educativo (BELLANDI, 2012, n.p, tradução nossa) ${ }^{3}$.

Os que não eram favoráveis ao projeto demonstravam sua preocupação, como o jornal italiano online Toscana Oggi (2008), cujos editores e leitores acreditavam que "Tinhase o risco [...] da banalização, devido sobretudo ao fato que se colocava a Divina Comédia nas mãos de 'um cômico'” (LETTERE, 2008, n.p, tradução nossa)4. Em certa ocasião, Vittorio Sermonti, um dos grandes estudiosos de Dante, conforme publicação cultural na revista eletrônica Fanpage.it (2016), declarou:

O seu modo de atualizar Dante é divertido, mas não se pode dizer tolices e coisas um pouco óbvias, apenas para atrair o público. Isso não é um bom serviço feito ao Poeta e muito menos aos expectadores. Tenho 78 anos e me desagrada deixar campo para este tipo de divulgação alegre. Dante é duro e severo e se requer dureza e severidade para entendê-lo. É uma operação delicadíssima, que não se pode fazer de qualquer maneira

\footnotetext{
1 Silvio Berlusconi, político italiano, foi primeiro-ministro da Itália nos anos de 1994 e 1995, 2001 a 2006 e 2008 a 2011. Ao longo dos seus mandatos, se envolveu em diversos escândalos, tanto relacionados à sua administração pública, quanto à sua vida pessoal (BERLUSCONI, 2013).

2 "Ho un sogno: fare tutta la Divina Commedia, commentarla e leggerla in pubblico, come mai è stato fato" (BELLANDI, 2012, n.p).

${ }^{3}[. .$.$] hanno avuto il merito di presentare il capolavoro dantesco al di fuori dalle aule scolastiche o dai circoli$ intellettuali in cui era rimasto per troppo tempo confinato, facendone vedere al grande pubblico la straordinaria attualità e portata educativa (BELLANDI, 2012, n.p).

4 "C'era il rischio [...] della banalizzazione, dovuta soprattutto al fatto che si metteva la Divina Commedia nelle mani di 'un comico"” (LETTERE, 2008, n.p).
} 
(QUANDO, 2016, n.p, tradução nossa) ${ }^{5}$.

Se de um lado temos a crítica, de outro temos o público, aquele que recebe a performance (ZUMTHOR, 2007), recuperando a epígrafe desse texto, na qual Benigni também se dirige ao público ao afirmar que a poesia se concretiza naquele que a escuta (BENIGNI, 2012). Com Boccaccio, quem escutou a Divina Comédia foi, em sua maioria, o povo florentino e alguns literatos. Com Sermonti, devido a transmissão via rádio, possivelmente, um número maior de pessoas pode ter contato com a obra dantesca. Já em Tutto Dante, a Europa e o continente americano puderam ouvir a obra. Nas apresentações na Piazza Santa Croce (Florença), Benigni levou cerca de 5 mil pessoas ao espetáculo. Com isso, o receio logo deu espaço ao reconhecimento pelo trabalho feito, ao render a Benigni o título de doutor honoris causa em filologia moderna da Universidade de Florença, "pela genial atitude de se pôr a serviço da literatura italiana e na interpretação de Dante e da Divina Comédia em particular, uma vocação cênica e atuável, digna da melhor tradição do espetáculo antigo e moderno" (ITALIA, 2007, n.p, tradução nossa) ${ }^{6}$.

Como já apontado anteriormente aqui, a performance é composta por vários elementos, a saber, um corpo que, por meio da vocalização, emite uma mensagem e, do outro lado, um corpo que a recebe. No presente caso, o responsável por dar voz à Divina Comédia foi Roberto Benigni. No projeto Tutto Dante, Benigni, mais do que ler os cantos dantescos, os declamou, deu vida ao poema, impôs sua marca, transparecida por meio do seu acento característico e do gestual marcante:

Declamar: declamar não é gritar. Não, em todo caso é falar com afeto e veemência. Recitar prosa ou verso com entonação e gestos convincentes. [...]

Cada novo poema exige uma revisão dos recursos sensíveis e, por que não, técnicos disponíveis para abordá-los. Toda a poesia se pode declamar, porque a declamação, em todos os tempos tem sido útil para dar-lhe vida, relevo, brilho ou opacidade aos versos inumeráveis poetas (CARRERA, 2014, p. 107).

De Benigni destacamos a voz, uma vez que ela é uma das responsáveis pela propagação dessa poesia. Como apontado por Arturo Carrera (2014), ao vocalizar um poema, não basta, simplesmente, lê-lo ou gritá-lo, cada composição poética tem sua melodia e cabe ao emissor encontrá-la, dando vida, relevo e brilho à obra. Paul Valéry (1999), no texto Da dicção de versos, fala dessa acomodação do verso por meio do canto, quando não só cada poema tem a sua estrutura, mas cada intérprete tem de achar o seu

\footnotetext{
5 "Il suo modo di attualizzare Dante è divertente ma non si possono dire spiritosaggini e cose un po' ovvie per adescare il pubblico. Questo non è un buon servizio fatto al Poeta e nemmeno agli ascoltatori. Ho 78 anni e mi dispiace lasciare il campo a questo tipo di divulgazione allegra. Dante è duro e severo e ci vuole durezza e severità per capirlo. Ė un'operazione delicatissima, che non si può fare alla buona" (QUANDO, 2016, n.p, grifos no original).

6 " [...] per la geniale attitudine a porre al servizio della letteratura italiana e nell'interpretazione di Dante e della Commedia in particolare, una vocazione scenica e attoriale degna della migliore tradizione dello spettacolo antico e moderno" (ITALIA, 2007, n.p).
} 
tom nesse conjunto. Para tanto, Valéry (1999) aconselha:

[...] ao estudar uma peça de poesia que se quer fazer escutar, não se deve tomar como origem ou ponto de partida da tentativa o discurso ordinário e a palavra corrente para elevar-se depois dessa prosa plana até o tom poético desejado; ao contrário, pensava eu que seria preciso apoiar-se no canto, colocar-se no estado do cantor, acomodar a voz à plenitude do som musical, e a partir daí descer ao estado algo menos vibrante que convém ao verso. Parecia-me que esse era o único meio de preservar a essência musical dos poemas. Antes de tudo, estudar o texto do ponto de vista dos ataques, modulações e tessituras que ele venha a carregar, e reduzir pouco a pouco tal disposição, a princípio exagerada, até as proporções da poesia (VALÉRY, 1999, p. 104).

De Boccaccio, não se imagina qual música sua voz imprimiu na Divina Comédia. Mas de Sermonti e Benigni podemos inferir que, apesar da obra ser a mesma, cada um impôs suas características. Ao escutar as transmissões radiofônicas da terza rima de Dante na voz de Sermonti, o ouvinte se depara com um tom linear e versos bem marcados, fatos confirmados por ele mesmo, quando afirmou que a declamação da Divina Comédia exigia "durezza e severità". Já com Benigni, talvez porque, além da voz, ter-se o aparato visual da performance, nos deparamos com uma apresentação enfática, com diferentes modulações da voz. E, apesar do temor da crítica, e do próprio Sermonti, de que a Divina Comédia, na voz de um comediante, seria um rebaixamento, Benigni conseguiu, ao colocar sua personalidade, afastar a comicidade, levando o público do riso à reflexão. A verve satírica de Benigni ficou restrita, dentro do espetáculo, à crítica ao governo da época.

\section{Considerações finais}

A proposta inicial deste artigo foi fazer um percurso breve sobre a performance e suas componentes, passando pela voz e vendo, na vocalização do poema, uma forma de mantêlo vivo. Para tanto, além dos conceitos-chave, para exemplificá-los, utilizamos a obra Divina Comédia, de Dante Alighieri que, apesar de escrita, se tornou ainda mais conhecida por meio de algumas performances.

A escrita serve para registrar, manter arquivado algo, como foi o caso de Dante: "A escrita toma parte no projeto de eternização" (ASMANN, 2011, p. 195); logo, escreve-se para não se esquecer. Já no tempo dos maias, incas e astecas a escrita era utilizada como suporte do que era vocalizado. Acreditava-se que o dispositivo escrita, além de um apoio à memória, que estaria disponível para consulta sempre que necessário, fosse uma forma de se manter a salvo do tempo o que fora produzido. Contudo, constatou-se que, devido à ação do próprio tempo, e ainda mais à rapidez da evolução tecnológica, arquivos escritos podem se tornar obsoletos rapidamente, tornando-se muitas vezes inacessíveis. Por sua vez, se o que era apenas oral encontrou, na escrita, uma forma de permanecer, o caminho contrário também pode ser verdadeiro, já que a escrita encontrou, na sua oralidade, uma forma de se propagar.

Performance, segundo Taylor (2013), engloba a transmissão de conhecimento e a 
memória, objetivando a formação de uma identidade. A Divina Comédia dantesca contribuiu e contribui para a formação crítica, sendo base para a formação, ao menos linguística, de um povo. De acordo com Taylor, Joseph Roach coloca a performance no mesmo patamar da memória e da história, enquanto forma de transferência e continuidade de conhecimento (TAYLOR, 2013). Ao performatizar a obra dantesca, Benigni reiterou ainda mais a propagação dos saberes contidos nessa obra literária.

Taylor (2013) também afirmou que a performance é uma inserção política. Se Dante, no século XIV, escreveu uma obra para mostrar ao homem sua degradação por conta dos pecados cometidos, não ao acaso, tal obra continua sendo recuperada sete séculos depois, para mostrar que o homem ainda não conseguiu se libertar dessas amarras, que ainda há um longo caminho a percorrer para a sua salvação.

$\mathrm{Na}$ esteira do entendimento de que a performance tem relação com uma cultura, Turner ratifica que "as performances revelavam o caráter mais profundo, mais verdadeiro e mais individual da cultura", "as populações poderiam aprender a compreender umas às outras por meio de suas performances" (TAYLOR, 2013, p. 28). Porém, além de ajudar a compreender uns aos outros, as performances também têm um caráter muito particular, no ponto em que contribuem para um entendimento do indivíduo, tal como a própria Divina Comédia que, por trás dessa viagem ao mundo dos mortos, proposta ao leitor, esconde, na verdade, um chamado a um olhar mais consciente para dentro de si.

\section{Referências}

A VIDA é bela. Produção de Gianluigi Braschi e Elda Ferri. [S.I.]: Melampo Cinematografia, 1997. 116 min, color.

ASSMANN, Aleida. Espaços da recordação: formas e transformações da memória cultural. Tradução de Paulo Soethe. São Paulo: UNICAMP, 2011.

BELLANDI, Andrea. Opinioni \& Commenti: Fra Benigni e Dante un confronto vivace e leale. Toscana Oggi, Firenze, 18 jul. 2012. Disponível em: https://www.toscanaoggi.it/OpinioniCommenti/Fra-Benigni-e-Dante-un-confronto-vivace-e-leale. Acesso em: 20 jan. 2020.

BENIGNI, Roberto. Opinioni \& Commenti: Fra Benigni e Dante un confronto vivace e leale. [Entrevista concedida a] Andrea Bellandi. Toscana Oggi, Firenze, 18 jul. 2012. Disponível em: https://www.toscanaoggi.it/Opinioni-Commenti/Fra-Benigni-e-Dante-un-confrontovivace-e-leale. Acesso em: 20 jan. 2020.

BERLUSCONI: uma vida marcada por escândalos. BBC News Brasil, 2 ago. 2013. Disponível em: https://www.bbc.com/portuguese/noticias/2013/08/130801_berlusconi_perfil_lgb. Acesso em: 27 jun. 2020.

CARRERA, Arturo. O homem mais portátil do mundo. Trad. de Marcelo Reis de Mello e Renato Rezende. Rio de Janeiro: Azougue: Circuito, 2014. 
FERREIRA, Jerusa Pires. Posfácio: a letra e a voz de Paul Zumthor. In: ZUMTHOR, Paul. A letra e a voz: a "literatura" medieval. Trad. de Amálio Pinheiro e Jerusa Pires Ferreira. São Paulo: Companhia das Letras, 1993, p. 287-296.

ITALIA: Università Firenze, laurea honoris causa in filologia moderna a Roberto Benigni. Toscana Oggi, Firenze, 28 jun. 2007. Disponível em: https://www.toscanaoggi.it/Italia/UNIVERSITA-FIRENZE-LAUREA-HONORIS-CAUSA-INFILOLOGIA-MODERNA-A-ROBERTO-BENIGNI. Acesso em: 20 jan. 2020.

ITALIANO Roberto Benigni leva Dante Alighieri aos EUA. Reuters. [S.I.], 25 maio 2009. Disponível em: http://g1.globo.com/Noticias/Cinema/0,,MUL11667107086,00ITALIANO+ROBERTO+BENIGNI+LEVA+DANTE+ALIGHIERI+AOS+EUA.html. Acesso em: 20 jan. 2020.

KIRK, G. S. Homer and the epic. Cambridge: Cambridge University Press, 1965.

KIRK, G. S. The songs of Homer. Cambridge: Cambridge University Press, 1962.

LETTERE: La sorpresa del Dante di Benigni. Toscana Oggi, Firenze, 2008. Disponível em: https://www.toscanaoggi.it/Lettere/La-sorpresa-del-Dante-di-Benigni. Acesso em: 20 jan. 2020.

LORD, Albert Bates. The singer of tales. Cambridge, Massachusetts: Harvard University Press, 1960.

OLIVEIRA, Gustavo Junqueira Duarte. Homero: oralidade, tradição e história. Nau Literária: revista eletrônica de crítica e teoria de literaturas. Porto Alegre, v. 4, n. 1, p. 1-22, jan./jun. 2008.

PARRY, Milman. Studies in the Epic Technique of Oral Verse-Making II. The Homeric Language as the Language of an Oral Poetry. Harvard Studies in Classical Philology, v. 43, p. 1-50, 1932.

PICCAROLO, Antonio. Dante Alighieri e sua obra. In: ALIGHIERI, Dante. A Divina Comédia. Trad. de José Pedro Xavier Pinheiro. São Paulo: Edigraf. 1946, p. XI-LXII.

QUANDO Vittorio Sermonti criticò Roberto Benigni su Dante e sulla 'Divina Commedia'. Fanpage, Napoli. 24 nov. 2016. Disponível em: https://www.fanpage.it/cultura/quandovittorio-sermonti-critico-roberto-benigni-su-dante-e-sulla-divina-commedia/. Acesso em: 20 jan. 2020.

STERZI, Eduardo. Por que ler Dante. São Paulo: Globo, 2008.

TAYLOR, Diana. Atos de transferência. In: TAYLOR, Diana. $O$ arquivo e o repertório: performance e memória cultural nas Américas. Trad. de Eliana Lourenço de Lima Reis. Belo Horizonte: UFMG, 2013, p. 25-90.

VALÉRY, Paul. De la dicción de versos. In: VALÉRY, Paul. Piezas sobre arte. Trad. de José Luis Arantegui. Madrid: Visor, 1999, p. 101-106.

WEST, Martin Litschfield. Homero: a transição da oralidade à escrita. Letras Clássicas, São Paulo, n. 5, p. 11-28, 2001. 
ZUMTHOR, Paul. A letra e a voz: a "literatura" medieval. Trad. de Amálio Pinheiro e Jerusa Pires Ferreira. São Paulo: Companhia das Letras, 1993.

ZUMTHOR, Paul. Performance, recepção, leitura. Trad. de Jerusa Pires Ferreira e Suely Fenerich. São Paulo: Cosac Naify, 2007.

\section{NOTAS DE AUTORIA}

Fernanda Moro Cechinel (fernandamcechinel@yahoo.com.br) é doutoranda em Literatura (UFSC). Bolsista Capes DS. Mestre em Literatura (UFSC). Licenciada em Letras - Língua Italiana e Literatura (UFSC). Bacharel em Turismo Gestão Hotelaria (Unisul). Atualmente, pesquisa a influência paratextual na leitura das obras literárias a partir das edições brasileiras da Divina Comédia, de Dante Alighieri, publicadas no século $\mathrm{XX}$.

\section{Como citar esse artigo de acordo com as normas da ABNT}

CECHINEL, Fernanda Moro. A Divina Comédia: da escrita de Dante à performance de Benigni. Anuário de Literatura, Florianópolis, v. 26, p. 01-12, 2021.

\section{Contribuição de autoria}

Não se aplica.

\section{Financiamento}

O presente trabalho foi realizado com apoio da Coordenação de Aperfeiçoamento de Pessoal de Nível Superior - Brasil (CAPES) - Código de Financiamento 001.

\section{Consentimento de uso de imagem \\ Não se aplica.}

\section{Aprovação de comitê de ética em pesquisa}

Não se aplica.

\section{Conflito de interesses}

Não se aplica.

\section{Licença de uso}

Os/as autores/as cedem à Revista Anuário de Literatura os direitos exclusivos de primeira publicação, com o trabalho simultaneamente licenciado sob a Licença Creative Commons Attribution (CC BY) 4.0 International. Estra licença permite que terceiros remixem, adaptem e criem a partir do trabalho publicado, atribuindo 0 devido crédito de autoria e publicação inicial neste periódico. Os autores têm autorização para assumir contratos adicionais separadamente, para distribuição não exclusiva da versão do trabalho publicada neste periódico (ex.: publicar em repositório institucional, em site pessoal, publicar uma tradução, ou como capítulo de livro), com reconhecimento de autoria e publicação inicial neste periódico.

\section{Publisher}

Universidade Federal de Santa Catarina. Programa de Pós-graduação em Literatura. Publicação no Portal de Periódicos UFSC. As ideias expressadas neste artigo são de responsabilidade de seus/suas autores/as, não representando, necessariamente, a opinião dos/as editores/as ou da universidade.

\section{Histórico}

Recebido em: 21/03/2020

Revisões requeridas em: 10/06/2020

Aprovado em: 03/07/2020

Publicado em: 23/02/2021 